\title{
Gambaran Obesitas pada Siswa Sekolah Dasar di SD Pertiwi dan SD Negeri 03 Alai Padang
}

\author{
Rizqa Fiorendita Hadi ${ }^{1}$, Afriwardi ${ }^{2}$, Yusri Dianne Jurnalis ${ }^{3}$
}

\begin{abstract}
Abstrak
Obesitas merupakan permasalahan serius yang mulai menjadi perhatian di seluruh dunia. Pada beberapa dekade terakhir prevalensi obesitas pada anak mulai mengalami peningkatan. Tujuan dari penelitian ini adalah untuk melihat gambaran obesitas yang terjadi pada siswa sekolah dasar di SD Pertiwi dan SD Negeri 03 Alai Padang serta hubungan usia dan jenis kelamin dengan obesitas pada siswa di SD Pertiwi dan SD Negeri 03 Alai Padang. Penelitian ini bersifat deskriptif dengan desain cross sectional yang dilaksanakan pada bulan Agustus - September 2013. Populasi dari penelitian ini adalah semua murid kelas I sampai VI SD Pertiwi dan SD Negeri 03 Alai Padang. Sampel untuk pemeriksaan berat badan, tinggi badan, dan IMT yang memenuhi kriteria inklusi dan ekslusi berjumlah 93 anak. Data diperoleh dengan melakukan pemeriksaan tinggi badan, berat badan, dan IMT dengan menggunakan kurva BMICDC 2000. Siswa yang terpilih secara acak di SD Pertiwi dan SD Negeri 03 Alai dilakukan pengukuran berat badan, tinggi badan, dan IMT, didapatkan frekuensi obesitas pada anak adalah sebesar 10,8\%. Frekuensi obesitas lebih tinggi pada siswa laki-laki (13\%). Kejadian obesitas banyak ditemukan pada anak berusia $>9$ tahun yaitu $14,7 \%$. Berdasarkan hasil uji statistik yang dilakukan dengan metode chi square, tidak terdapat hubungan yang bermakna antara usia dan jenis kelamin dengan obesitas pada siswa sekolah dasar $(p>0,05)$.
\end{abstract}

Kata kunci: obesitas, usia, jenis kelamin

\section{Abstract}

Obesity is a serious problem that is starting to become a worldwide concern. In recent decades the prevalence of obesity in children began to increase around the world. The purpose of this study is to see an overview of obesity that occurs in primary school students in SD Pertiwi and SD Negeri 03 Alai Padang and the relationship of age and gender to obesity in SD Pertiwi and SD Negeri 03 Alai Padang. This study is a descriptive cross- sectional design and the study was conducted in August-September 2013. Population of the study were all students of class I to VI of SD Pertiwi and SD Negeri 03 Alai Padang. Sample for weight, height, and BMI which meets the criteria for inclusion and exclusion amounts to 93 children. Data obtained by examination of height, weight, and BMI using the BMI - CDC 2000 curves. Randomly selected students in SD Pertiwi and SD Negeri 3 Alai Padang were measured the weight, height, and BMI, the frequency of obesity in children amounted to $10.8 \%$. The frequency of obesity was higher in boys (13\%). Incidence of obesity are mostly found in children aged $>9$ year-old (14.7\%). According to the results of statistical tests conducted using chi-square, there was no significant association between age and sex with obesity in elementary school children ( $p>0.05$ ).

Keywords: obesity, age, sex

Affiliasi penulis : 1.Fakultas Kedokteran Universitas Andalas, 2. Bagian Fisiologi Fakultas Kedokteran Universitas Andalas, 3. Bagian IImu Kesehatan Anak Fakultas Kedokteran Universitas Andalas Korespondensi : Rizqa Fiorendita Hadi, email : rizqafiorenditahadi@gmail.com, Telp: 085274547945

\section{PENDAHULUAN}

Obesitas merupakan permasalahan serius yang mulai menjadi perhatian di seluruh dunia. Definisi obesitas adalah terjadinya peningkatan berat badan yang disebabkan oleh bertambahnya jaringan lemak 
tubuh secara berlebihan pada individu. ${ }^{1}$ Penelitian yang dilakukan di Amerika Serikat pada tahun 20072008 melaporkan bahwa 11,9\% anak-anak dan remaja berusia 2 sampai 19 tahun berada pada atau di atas persentil 97 pada grafik pertumbuhan BMI berdasarkan usia; $16,9 \%$ berada pada atau diatas persentil 95; dan 31,7\% berada pada atau di atas persentil $85 .^{2}$ Peningkatan angka prevalensi terhadap kasus obesitas pada anak tersebut tidak hanya terjadi di negara maju, tetapi juga terjadi di negara berkembang. $^{3}$ Berdasarkan data Riskesdas 2010 mengenai prevalensi obesitas pada anak sekolah dasar usia 7 - 12 tahun di Indonesia, Sumatera Barat mengalami penurunan angka kejadian obesitas pada anak dibandingkan pada tahun 2007 yaitu dari 6,4\% menjadi 3,8\%. ${ }^{4}$

Faktor-faktor yang berperan dalam peningkatan prevalensi obesitas terbagi menjadi dua, yaitu faktor yang dapat diubah dan tidak dapat diubah. Menurut data Riskesdas (2007) obesitas lebih banyak dijumpai pada anak laki-laki dibandingkan dengan anak perempuan. Sementara itu menurut kategori umur, kejadian obesitas lebih banyak dtemukan pada anak berusia 6-9 tahun dibandingkan dengan anak berusia 10-14 tahun., ${ }^{5,6} \mathrm{Hal}$ ini berkaitan dengan terjadinya periode kritis perkembangan obesitas yaitu pada usia lima hingga tujuh tahun. ${ }^{7}$ Dua faktor yang dapat diubah yang dapat menyebabkan obesitas adalah peningkatan intake kalori dan penggunaan energi yang rendah. $^{8}$ Sebagai keadaan patologis, obesitas pada anak memiliki kemungkinan untuk mengalami komplikasi penyakit lain, terutama penyakit metabolik, pada masa dewasa. Terjadinya komplikasi akibat obesitas berhubungan dengan angka morbiditas dan mortalitas penyakit dengan obesitas sebagai faktor risikonya. ${ }^{9}$

Berdasarkan survei awal yang dilakukan terhadap SD Pertiwi dan SD Negeri 03 Alai Padang, didapatkan data bahwa beberapa diantara murid sekolah tersebut memiliki IMT di atas persentil 85 . Lokasi sekolah juga terletak di pusat kota dan tingkat perekonomian orangtua murid rata-rata berada pada posisi menengah ke atas. Berdasarkan hal tersebut, maka peneliti tertarik mengadakan penelitian untuk mengetahui gambaran obesitas anak pada siswa sekolah dasar di SD Pertiwi dan SD Negeri 03 Alai Padang.

\section{METODE}

Penelitian ini merupakan jenis survey dengan menggunakan studi deskriptif dengan rancangan penelitian cross sectional yang dilaksanakan pada bulan Agustus hingga September 2013. Populasi dari penelitian ini adalah Semua siswa kelas I sampai VI SD yang obesitas di SD Pertiwi dan SD Negeri 03 Alai berjumlah 1380 anak. Sampel untuk pemeriksaan obesitas adalah seluruh murid kelas I sampai VI SD yang terpilih secara acak yaitu sebanyak 93 orang. Data diperoleh dengan melakukan pengukuran antropometri pada siswa SD dengan menggunakan kurva BMI-CDC 2000.

Data yang diperoleh dari pemeriksaan antropometri dan IMT dikelompokkan berdasarkan umur dan jenis kelamin. Kemudian hasil yang diperoleh disajikan dalam bentuk tabel distribusi frekuensi.

\section{HASIL}

Penelitian ini dilakukan di SD Pertiwi dan SD Negeri 03 Alai Padang pada Agustus - September 2013. Penelitian ini dilaksanakan di SD Pertiwi dan SD Negeri 03 Alai dengan jumlah sampel sebanyak 93 orang. Data total siswa dan siswi didapatkan dari daftar absensi di setiap kelas masing-masing sekolah. Seluruh sampel dilakukan pengukuran antropometri dan IMT, dan didapatkan 10 orang anak mengalami obesitas.

Tabel 1. Karakteristik Sampel Berdasarkan Hasil Perhitungan Statistik

\begin{tabular}{lcc}
\hline $\begin{array}{c}\text { Karakteristik } \\
\text { Jenis Kelamin } \\
\text { Laki-laki }\end{array}$ & $\mathbf{n}$ & $\%$ \\
Perempuan & 47 & 50.5 \\
Usia & & \\
Mean & 8,89 & \\
Standar deviasi & 1,760 & \\
Median & 9,00 & \\
Maximum & 12 & \\
Minimum & 6 & \\
\hline
\end{tabular}

Tabel 1 menunjukkan karakteristik sampel 
yaitu berupa jenis kelamin dan usia. Jumlah sampel berjenis kelamin laki-laki adalah 46 orang dan jenis kelamin perempuan adalah 47 orang. Usia maksimum sampel adalah 12 tahun sementara usia minimum adalah 6 tahun, mean yaitu 8,89 tahun, dan median yaitu 9,00 tahun.

Tabel 2. Karakteristik Sampel Berdasarkan Usia dan Jenis Kelamin pada Siswa SD Pertiwi dan SD Negeri 03 Alai Padang

\begin{tabular}{lll}
\hline \multicolumn{1}{c}{ Karakteristik } & Jumlah & $\%$ \\
\hline Usia & & \\
$\leq 9$ tahun & 59 & 63,4 \\
$>9$ tahun & 34 & 36,6 \\
Jenis Kelamin & & \\
$\quad$ Laki-laki & 46 & 49,5 \\
$\quad$ Perempuan & 47 & 50,5 \\
\hline
\end{tabular}

Pada tabel 2 dapat dilihat bahwa sampel lebih banyak berada pada rentang usia $\leq 9$ tahun dibandingkan usia $>9$ tahun $(63,4 \%$ : 36,6\%). Berdasarkan jenis kelamin, sampel lebih banyak terdiri dari anak perempuan dibandingkan laki-laki $(50,5 \%$ : $49,5 \%)$.

Tabel 3. Distribusi Frekuensi Obesitas pada Siswa di SD Pertiwi dan SD Negeri 03 Alai Padang

\begin{tabular}{lcc}
\hline \multicolumn{1}{c}{ Interpretasi } & $\mathrm{f}$ & $\%$ \\
\hline Underweight & 17 & 18,2 \\
Normal & 57 & 61,3 \\
Overweight & 9 & 9,7 \\
Obesitas & 10 & 10,8 \\
\hline Jumlah & 93 & 100 \\
\hline
\end{tabular}

Berdasarkan tabel 3 dapat disimpulkan bahwa murid yang mengalami obesitas di SD Pertiwi dan SD Negeri 03 Alai berjumlah 10 orang (10,8\%).

Pada tabel 4 dapat dilihat bahwa berdasarkan usia, kejadian obesitas lebih banyak didapatkan pada anak usia >9 tahun dibandingkan dengan usia $\leq 9$ tahun (14,7\% : 8,5\%). Berdasarkan jenis kelamin kejadian obesitas banyak ditemukan pada anak lakilaki (13\%). Tidak terdapat hubungan antara usia anak dengan obesitas ( $p$ value $=0,489$ ) dan tidak terdapat hubungan antara jenis kelamin dengan obesitas ( $p$ value $=0,523$ ).

Tabel 4. Hubungan Usia dan Jenis Kelamin dengan Obesitas pada Siswa SD Pertiwi dan SD Negeri 03 Alai Padang

\begin{tabular}{cccc}
\hline & \multicolumn{2}{c}{ Interpretasi } & \\
\cline { 2 - 3 } Karakteristik & $\begin{array}{c}\text { Tidak } \\
\text { obesitas } \\
(\%)\end{array}$ & $\begin{array}{c}\text { Obesitas } \\
(\%)\end{array}$ & \\
& \multicolumn{1}{c}{ P value } \\
\hline Usia & & & \\
$\leq 9$ tahun & $54(91,5)$ & $54(91,5)$ & 0,489 \\
$>9$ tahun & $29(81,3)$ & $29(81,3)$ & \\
Jenis Kelamin & & & \\
Laki-laki & $40(87)$ & $6(13)$ & 0,523 \\
Perempuan & $43(91,5)$ & $4(8,5)$ & \\
\hline
\end{tabular}

\section{PEMBAHASAN}

Penelitian dilakukan di dua SD yaitu SD Pertiwi dan SD Negeri 03 Alai. Pemilihan lokasi penelitian dilakukan secara acak. Jumlah sampel yang didapat pada penelitian ini adalah 93 orang yang dibagi secara proportional random sampling berdasarkan jumlah siswa pada masing-masing sekolah yang terpilih.

Berdasarkan penelitian yang dilakukan terhadap 93 siswa-siswi di SD Pertiwi dan SD Negeri 03 Alai Padang didapatkan prevalensi kejadian obesitas pada anak usia sekolah dasar adalah sebesar 10,8\%. Prevalensi ini cukup tinggi jika dibandingkan dengan prevalensi obesitas pada siswa sekolah dasar di Sumatera Barat pada menurut Riskesdas tahun 2010 yaitu sebesar 3,8\%. ${ }^{4}$ Penelitian yang dilakukan di Cina mendapatkan prevalensi obesitas pada anak usia sekolah sebesar $4,11 \%$. $^{11}$ Penelitian yang dilakukan di negara maju seperti Kanada didapatkan prevalensi obesitas pada siswa tingkat 5 adalah sebesar $9,9 \%{ }^{14}$

Berdasarkan hasil penelitian yang dilakukan terhadap 93 orang sampel didapatkan 46 orang $(49,5 \%)$ berjenis kelamin laki-laki dan 47 orang $(50,5 \%)$ berjenis kelamin perempuan. Dari data yang didapatkan di lapangan kejadian obesitas lebih banyak terjadi pada anak laki-laki (13\%) dibandingkan dengan 
perempuan (8,5\%). Hal ini sejalan dengan penelitian di beberapa sekolah dasar di Semarang Barat yaitu kejadian obesitas lebih tinggi ditemukan pada anak laki-laki $(57,1 \%)$ dibandingkan perempuan $(42,9 \%) .{ }^{12}$ Penelitian di Swiss juga menemukan bahwa perbandingan kejadian obesitas pada anak laki-laki dengan anak perempuan yaitu 6,2\%:4,2\%. ${ }^{15}$ Berbeda dengan sebuah penelitian yang dilakukan di kota Manado dari 111 anak yang dinyatakan obesitas jumlah anak perempuan yang obesitas (57 orang) sedikit lebih banyak dibandingkan laki-laki (54 orang). ${ }^{16}$

Dari hasil penelitian yang dilakukan terhadap 93 orang sampel didapatkan data bahwa kejadian obesitas banyak ditemukan pada rentang usia >9 tahun dibandingkan dengan usia $\leq 9$ tahun yaitu sebesar 14,7\%: 8,5\%. Dasar peneliti memilih usia 9 tahun sebagai patokan umur adalah berdasarkan perhitungan statistik di mana mean umur yang didapatkan adalah 8,89 tahun. Mean digunakan sebagai patokan untuk batasan umur karena data statistik yang didapatkan tidak terdistribusi sempurna. Hasil ini sejalan dengan penelitian lain yang menemukan bahwa kejadian obesitas lebih banyak dialami anak berusia 11 tahun. ${ }^{17}$ Penelitian di Iran juga menemukan persentase obesitas terendah adalah pada usia 7 tahun. $^{18}$ Penelitian di Cina juga mendapatkan prevalensi obesitas yang lebih tinggi pada rentang usia 10 hingga 12 tahun dibandingkan dengan rentang usia lainnya. ${ }^{11}$

Penelitian lain yang dilakukan pada anak usia sekolah dasar di Cina mendapatkan prevalensi tertinggi dari obesitas didapatkan pada rentang usia 7 hingga 9 tahun. $^{19}$ Perbedaan usia anak yang mengalami obesitas bervariasi di setiap penelitian karena memiliki kaitan dengan faktor-faktor predisposisi obesitas lainnya seperti ras/etnik, pola makan, dan aktivitas fisik.

Berdasarkan hasil penelitian yang dilakukan pada 93 orang sampel yang merupakan siswa usia sekolah dasar, tidak didapatkan hubungan antara usia anak dengan obesitas yang terjadi pada anak ( $p$ value $=0,489)$. Risiko obesitas dapat terjadi pada tiap rentang usia sekolah dasar yaitu dari 6 hingga 12 tahun sehingga usia tidak mempengaruhi kejadian obesitas pada anak usia sekolah dasar. Namun menurut salah satu penelitian di India kejadian obesitas akan berkurang seiring dengan pertambahan usia karena munculnya sikap pemalu pada remaja post-pubertas dibandingkan dengan anak-anak. ${ }^{20}$

Dari hasil penelitian yang dilakukan tidak didapatkan hubungan antara jenis kelamin anak dengan obesitas ( $p$ value $=0,523$ ). Anak laki-laki maupun anak perempuan memiliki risiko yang sama untuk mengalami obesitas sehingga jenis kelamin anak tidak mempengaruhi kejadian obesitas pada anak usia sekolah dasar. Namun dalam sebuah penelitian didapatkan bahwa peningkatan tren obesitas pada anak laki-laki yang bertolak belakang dengan stabilisasi pada anak perempuan, seperti yang juga diteliti pada populasi dewasa. ${ }^{21}$ Sementara itu pada penelitian lain didapatkan prevalensi obesitas yang lebih tinggi pada anak perempuan dibandingkan dengan anak laki-laki, yang berkaitan dengan perbedaan sifat hormonal. ${ }^{13}$

\section{KESIMPULAN}

Prevalensi obesitas pada siswa SD Pertiwi dan SD Negeri 03 Alai adalah sebesar 10,8\%.

Tidak terdapat hubungan antara usia dengan kejadian obesitas yang terjadi pada anak.

Tidak terdapat hubungan antara jenis kelamin dengan kejadian obesitas pada anak.

\section{DAFTAR PUSTAKA}

1. Sjarif DR. Obesitas pada Anak dan Permasalahannya. Dalam: Trihono PP, Purnamawati, editor (penyunting). Hot Topics in Pediatrics II. Jakarta: Balai Penerbit FKUI; 2002. HIm. 219-34.

2. Ogden CL, Caroll M. Prevalence of Obesity Among Children and Adolescents: United States, Trends 1963-1965 Through 2007-2008. NCHS; 2010. hlm. 1-5.

3. De Onis M, Blössner M. Prevalence and Trends of Overweight Among Preschool Children in Developing Countries. The Amr J Clin Nutr. 2000;72(4);1032.

4. Depkes RI. Riset Kesehatan Dasar (Riskesdas). Jakarta : Depkes RI. 2010.

5. Depkes RI. Riset Kesehatan Dasar (Riskesdas). Jakarta : Depkes RI. 2007. 
6. Musadat A. Analisis Faktor-Faktor yang Mempengaruhi Kegemukan pada Anak Usia 6-14 Tahun di Provinsi Sumatera Selatan. Tesis, Institut Pertanian Bogor, Bogor; 2010.

7. Arisman. Obesitas, Diabetes Mellitus, dan Dislipidemia: Konsep, Teori, dan Penanganan Aplikatif. Jakarta: Penerbit Buku Kedokteran EGC; 2007.

8. Nemet D, Barkan S, et al. Short- and Long-term Beneficial Effects of A Combined DietaryBehavioral-Physical Activity Intervention for The Treatment of Childhood Obesity. Pediatrics. 2005;115(4);443-9.

9. Rompis J, Kaunang ED. Relationship Between Obesity and Left Ventricular Hypertrophy in Children. Paediatr Indones. 2010;50(6);331-5.

10. Epstein LH, Paluch RA, et al. Decreasing Sedentary Behaviors in Treating Pediatric Obesity. Arch Pediatr Adolesc Med. 2000;154;220-6.

11. Yi $X Q, Y i n C Y$, et al. Prevalence and Risk Factors of Obesity Among School-aged Children in Xi'an, China. Eur J Pediatr. 2012;171;389-94.

12. Sari, VP. Perbedaan Prestasi Belajar Antara Anak Sekolah Dasar Penderita Obesitas dan Status Gizi Normal (Studi Penelitian pada Siswa Sekolah Dasar Kelas 3 - 5 di SD Nasima Kecamatan Semarang Barat Tahun 2012). JKM. 2012;1(2);627-34.

13. Mahajan PB, Purty AJ, et al. Study of Childhood Obesity Among School Children Aged 6 to 12 years in Union Territory of Puducherry. Indian $\mathrm{J}$ Community Med. 2011;36;45-50.

14. Veugelers PJ, Fitzgerald AL. Prevalence of and Risk Factors for Childhood Overweight and
Obesity. Canadian Medical Association Journal. 2005;173(6);607.

15. Aerbeli I, Henschen I, et al. Stabilisation of the Prevalence of Childhood Obesity in Switzerland. Swiss Med Wkly. 2010:140:w13046.

16. Lumoindong $A$, Umboh $A$, et al. Hubungan Obesitas dengan Profil Tekanan Darah pada Anak Usia 10 - 12 Tahun di Kota Manado. Skripsi, Universitas Sam Ratulangi, Manado; 2012.

17. Mariza YY, Kusumastuti AC. Hubungan antara Kebiasaan Sarapan dan Kebiasaan Jajan dengan Status Gizi Anak Sekolah Dasar di Kecamatan Pedurungan Kota Semarang. Journal of Nutrition College; 2013;2(1);207-13.

18. Hajian-Tilaki KO, Sajjadi $P$, et al. Prevalence of Overweight and Obesity and Associated Risk Factors in Urban Primary-school Children in Babol, Islamic Republic of Iran. EMHJ. 2011:17(2).

19. Song Y, Wang HJ, et al. Secular Trends of Obesity Prevalence in Urban Chinese Children from 1985 to 2010: Gender Disparity. PloS ONE.2013:8(1):e53069.

20. Gupta N, Goel K, et al. Childhood Obesity in Developing Countries: Epidemiology, Determinants, and Prevention. Endocrine Reviews. 2012:33:48-70.

21. Serra-Majem L, Ribas-Barba L, et al. Methodological Limitation in Measuring Childhood and Adolescent Obesity and Overweight in Epidemiological Studies : Does Overweight Fare Better than Obesity?. Public Health Nutrition. 2007:10(10A):1112-20. 